\title{
ASPECTOS SOCIOCIENTÍFICOS E A QUESTÃO AMBIENTAL: UMA DIMENSÃO DA ALFABETIZAÇÃO CIENTÍFICA NA FORMAÇÃO DE PROFESSORES DE QUÍMICA
}

\author{
SOCIOSCIENTIFIC ASPECTS AND THE ENVIRONMENTAL QUESTION: A \\ DIMENSION OF SCIENTIFIC LITERACY IN THE EDUCATION OF CHEMISTRY \\ TEACHERS
}

\author{
Rosana Franzen Leite \\ Universidade Estadual do Oeste do Paraná - Unioeste/Programa de Pós-Graduação em \\ Educação em Ciências e Educação Matemática - PPGECEM, rosana.leite@unioeste.br

\section{Maria Aparecida Rodrigues} \\ Universidade Estadual de Maringá - UEM/Programa de Pós-Graduação em Educação para a \\ Ciência e a Matemática - PCM, aparecidar@gmail.com
}

\begin{abstract}
Resumo
Neste artigo, discutimos o entendimento de acadêmicos de um curso de QuímicaLicenciatura acerca dos aspectos sociocientíficos atrelados a questões ambientais. Participaram da pesquisa 51 estudantes do referido curso, de uma universidade estadual do Paraná, Brasil, que responderam a um questionário e a uma entrevista semiestruturada. Do conteúdo das respostas analisadas, emergiram: aspectos salvacionistas atribuídos à Ciência e à Tecnologia, bem como o pensamento de que os estudos científicos buscam sempre a solução dos problemas ambientais. Também foi possível identificar que a conscientização ambiental é para estes estudantes, um papel da educação, e que o aumento do lixo no ambiente está fortemente ligado ao consumismo. Somente alguns dos entrevistados conseguem identificar os aspectos sociocientíficos envolvidos nessa problemática, o que corrobora com a representação romântica e conservadora do papel da Ciência e da Tecnologia nas questões ambientais, presente no discurso da maioria dos participantes.
\end{abstract}

Palavras-chave: Ciência e Tecnologia, Formação Inicial, Ensino de Ciências

\begin{abstract}
In this article, we discuss the understanding of students of a chemistry teaching course as regards socioscientific aspects related to environmental questions. A total of 51 students from a Paraná state (Brazil) public university participated in the aforementioned course and responded to a questionnaire and semi-structured interview questions. The following emerged from the analyzed answers: salvationist aspects attributed to science and technology, as well as the impression that scientific studies always look for solutions to environmental problems. It was also possible to identify that environmental awareness for these students is a role of education, and that the increase in garbage in the environment is strongly linked to consumerism. Only some of the interviewees managed to identify the
\end{abstract}


socioscientific aspects involved in this issue, which corroborates the romantic and conservative representation of the role of science and technology in environmental questions present in the discourse of most of the participants.

Key words: science and technology, initial education, science teaching.

\section{Introdução}

Considerar, refletir, discutir e opinar sobre os aspectos sociocientíficos atrelados à questão ambiental tem se tornado cada vez mais uma exigência para os profissionais das áreas das ciências, em especial dos professores da área da Química. Ao mencionarmos tais perspectivas, acenamos à discussão de aspectos referentes às questões ambientais, políticas, econômicas, relativas à ciência e à tecnologia.

Se pensarmos em estratégias curriculares para a efetivação dessa discussão em sala de aula, indicaríamos inúmeros motivos para fazê-lo e que vão desde a problematização de questões sociais até a compreensão da natureza da atividade científica, passando, principalmente, pelo objetivo de possibilitar reflexão crítica de valores (SANTOS, 2007).

Os aspectos sociocientíficos estão diretamente ligados às ideias relativas aos currículos CTS (Ciência-Tecnologia-Sociedade) e à problematização das questões sociais, e, nas palavras de Sasseron e Carvalho (2011, p. 76), há "[...] a necessidade de se compreender as aplicações dos saberes construídos pelas ciências considerando que as ações podem ser desencadeadas pela utilização dos mesmos".

Por isso, as questões ambientais são exemplos simples da relação entre esses aspectos. Todas as abordagens, quer sejam elas educacionais, instrucionais ou informáticas, necessitam apontar os diferentes aspectos envolvidos:

Toda sua discussão não pode mais se pautar apenas em detalhes de proteção ecológica ou dita natural, sem que necessariamente nos pautemos nos demais aspectos envolvidos, nos interesses econômicos e sociais envolvidos. Tampouco devemos manter a crença ingênua de que basta um novo produto científico ou uma nova tecnologia para solucionar um problema pontual de alimentação ou de saúde, sem que isso acarrete outras alterações, em outras esferas (LEITE, 2015, p. 59).

Assim, concordamos com Auler e Delizoicov (2001, p. 10), ao discutirem sobre a ideia de Alfabetização Científica "ampliada", alfabetização na qual os conteúdos são os meios para o entendimento dos temas relevantes da sociedade, buscando "[...] a compreensão sobre as interações entre Ciência-Tecnologia-Sociedade, o que equivale, em outros termos, ao ensino de conceitos associado ao desvelamento de mitos vinculados à $\mathrm{CT}^{1}$ ". Tais mitos são: (i) superioridade do modelo de decisões tecnocráticas; (ii) perspectiva salvacionista da Ciência e Tecnologia; e (iii) determinismo tecnológico, sendo a

\footnotetext{
${ }^{1}$ Abreviação de Ciência e Tecnologia, para os autores, no original.
} 
neutralidade científica o "mito original". Tais mitos são descritos individualmente da seguinte forma:

a) Superioridade do modelo de decisões tecnocráticas: neste mito são discutidos os valores atribuídos à superioridade das decisões tecnocráticas, considerando o discurso científico como inquestionável, como sendo o mais importante, entendendo-se e valorizando-se a ciência de forma absoluta, tal como as igrejas consideram deus. Assim, a ciência - pura, sem ideologia - seria capaz de solucionar os problemas da sociedade.

b) Perspectiva salvacionista da Ciência e Tecnologia: os autores discutem a perspectiva salvacionista da Ciência e da Tecnologia, que, no processo linear de crescimento e progresso, sempre conduziria ao bem-estar social, ou seja, sempre estaria a serviço da humanidade.

c) Determinismo tecnológico: neste mito, os autores discutem a ideia determinística segundo a qual o avanço tecnológico é considerado como fator para as mudanças sociais, sendo também isento das influências dessa mesma sociedade e de suas necessidades reais (AULER e DELIZOICOV, 2001).

Essas crenças, ou ideias, são formadas ao longo do tempo, por nossa formação pessoal e profissional, contudo professores da área de Ciências devem ampliar as suas ideias relacionadas a essa temática, ou seja, aos aspectos sociocientíficos, uma vez que deverão ensinar sobre a ciência em geral e tudo que a afeta, e não apenas sobre os conhecimentos científicos puros.

Os autores Azevedo et al. (2012) analisaram a formação de professores ao longo de décadas, em nosso país, e se nos pautarmos nela, havemos de concluir que estamos na era do professor pesquisador-reflexivo. Esse padrão de professor deve possuir familiaridade com processos e produtos de pesquisa científica, buscando um trabalho docente mais intencional, crítico e autônomo.

Além disso, documentos oficiais de formação (graduação/licenciatura) de professores de Química, no nosso caso específico, e autores como Rossi e Ferreira (2008) discutem que cabe a esses professores, aos professores de Química, discutir questões que envolvam os aspectos sociais, econômicos e ambientais relacionados à ciência química, proporcionando subsídio teórico para que seus estudantes possam atuar em sociedade como cidadãos conscientes.

Cabe aqui mencionar que, em investigação anterior com professores de Química atuantes no ensino médio, sobre a abordagem de temas ambientais em aula de Química, os resultados demonstraram que, para eles, mais importante que propor novas metodologias de ensino no âmbito da sala de aula, é necessário formar adequadamente os professores para a abordagem desses aspectos. Os professores também revelaram algumas dificuldades: relacionar as questões ambientais aos conteúdos químicos, trabalhar com material direcionado para o tratamento de questões sociocientíficas, tais como determinado livro didático, que, por sua vez, se distancia do caráter tradicional de apresentação de conteúdos e, ainda, mencionaram certa insegurança em promover atividades inovadoras nessa área, pelo fato de não terem sido preparados para desenvolver tais atividades de ensino durante a formação docente inicial, ou seja, durante o curso de graduação, a licenciatura (LEITE, 2009). 
Sendo assim, a formação de professores de Química e de Ciências, necessita, em algum momento, desenvolver atividades - não apenas pontuais - que propiciem um preparo para o tratamento dos aspectos sociocientíficos nas aulas, na escola na qual esses professores trabalharão. Sobre isso explicam Rossi e Ferreira (2008):

O professor bem formado, crítico e consciente pode colaborar na discussão de questões atuais em suas aulas, baseado em conceitos químicos discutidos com propriedade e correção científica adequada para subsidiar a formação de opiniões. Pela sua participação na formação de seus estudantes como cidadãos conscientes, o professor é um dos melhores agentes para fomentar a sociedade em processos reflexivos, que podem amenizar o estigma da Química e até apresentar seu potencial profissional. (ROSSI e FERREIRA, 2008, p. 128-129, grifo nosso).

Compactuando com os autores, defendemos que, no período de formação inicial de professores de Química, o profissional, o professor formado, deve saber, além de outros elementos fundamentais: "[...] integrar seus conhecimentos práticos e específicos de Química às questões de ordem social e política, por exemplo, porque dessa integração surge a possibilidade de trabalhar em busca da reflexão e da discussão, junto aos seus estudantes" (LEITE, 2015,p.57 ). E assim, vê-se que é preciso vivenciar situações que propiciem tal formação.

\section{Aspectos Sociocientíficos como uma dimensão da alfabetização científica}

Discutir sobre Alfabetização Científica (AC) envolve delimitar, de certa forma, um entendimento, uma ideia pela qual se propõem as dimensões, os aspectos, as categorias... Sendo assim, assumimos, para tal estudo, o termo Alfabetização Científica no mesmo sentido das autoras Sasseron e Carvalho (2011), que, não distinguindo entre Alfabetização e Letramento, utilizam as ideias de Paulo Freire para alicerçar a escolha, dado que a ideia de alfabetização "[...] deve desenvolver em uma pessoa qualquer a capacidade de organizar seu pensamento de maneira lógica, além de auxiliar na construção de uma consciência mais crítica em relação ao mundo que a cerca" (SASSERON e CARVALHO, 2011, p. 61).

Da mesma forma, assumimos os pressupostos de Fourez (1997) - mesmo que este utilize o termo Alfabetização Científica e Tecnológica (ACT). Esse pensador, utilizando os critérios propostos pela $\mathrm{NSTA}^{2}$, afirma que uma pessoa alfabetizada científica e tecnologicamente é capaz de:

1. Utilizar conceitos científicos e integrar valores e saberes para adotar decisões responsáveis no seu cotidiano.

2. Compreender que a sociedade exerce um controle sobre as Ciências e as tecnologias e do mesmo modo que as ciências e as tecnologias imprimem seu selo na sociedade.

3. Compreender que a sociedade exerce um controle sobre as ciências e as tecnologias pela via das subvenções que lhes outorga.

4. Reconhecer tanto os limites como a utilidade das ciências e as tecnologias no progresso do bem-estar humano.

\footnotetext{
${ }^{2}$ NSTA: National Science Teachers Association
} 
5. Conhecer os principais conceitos, hipóteses e teorias científicas e ser capaz de aplicá-los.

6. Apreciar as ciências e as tecnologias pela estimulação intelectual que suscitam.

7. Compreender que a produção de saberes científicos depende dos processos de investigação e conceitos teóricos.

8. Saber conhecer as diferenças entre resultados científicos e opiniões pessoais.

9. Reconhecer a origem da ciência e compreender que o saber científico é provisório e sujeito a mudanças segundo o grau de acumulação dos resultados.

10. Compreender as aplicações das tecnologias e as decisões implicadas em sua utilização.

11. Possuir suficiente saber e experiência para apreciar o valor da investigação e desenvolvimento tecnológico.

12. Extrair de sua formação científica uma visão de mundo mais rica e interessante.

13. Conhecer as fontes válidas de informação científica e tecnológica e recorrer a elas quando tiver que tomar decisões.

14. Ter certa compreensão da maneira em que as ciências e as tecnologias foram produzidas na história. (FOUREZ, 1997, p. 25-36, tradução nossa).

O referido autor apresenta um entendimento de $\mathrm{AC}$ com o qual compactuamos e o assumimos neste trabalho, qual seja:

[...] a ACT é mais que aprender receitas ou mesmo comportamentos inteligentes frente à ciência e à tecnologia: envolve uma visão crítica e humanista da forma como a tecnologia (e também as tecnologias intelectuais, que são a ciência) moldam a nossa forma de pensar, organizar e agir (FOUREZ, 1997, p. 33, tradução nossa).

Como, contudo, estamos direcionando nossa ideia de AC para a formação de professores de Ciências, em especial de os professores de Química, consideramos necessário propor dimensões que destaquem as ideias essenciais. Para nós, a AC envolve: a) entendimento da natureza da ciência e dos conhecimentos científicos; b) identificação e reconhecimento da importância do significado dos conceitos e das teorias científicas nos processos diários, e c) clareza dos aspectos sociocientíficos envolvidos nas diversas situações da vida (LEITE, 2015). Retomamos a seguir essas dimensões para melhor explica-las:

a) entendimento da natureza da ciência e dos conhecimentos científicos: esta dimensão trata dos conhecimentos relativos às representações de ciência e de cientista, e como tais representações podem ser importantes nas aulas de Ciências/Química, bem como o entendimento da ciência como atividade humana e como o conhecimento científico é construído.

b) identificação e reconhecimento da importância do significado dos conceitos e das teorias científicas nos processos diários: nesta dimensão defendemos ser de grande relevância que os cidadãos não apenas reconheçam e utilizem os conceitos científicos diariamente, em situações em que se faça necessário, mas ainda que possam reconhecera valor desses conhecimentos, principalmente por se tratar de seu futuro como professores de Ciências/Química.

c) clareza dos aspectos sociocientíficos envolvidos em diversas situações da vida: esta dimensão se propõe a tratar de questões que envolvem aspectos ambientais, sociais, políticos e econômicos relativos à ciência e à tecnologia. E, ainda, sua importância para o 
Ensino de Ciências/Química, de forma a integrar os currículos.

De forma análoga, em um dos primeiros e mais importantes trabalhos sobre AC, Jon D. Miller (1983) apresenta três dimensões para o conceito de AC: o entendimento da natureza da ciência, das suas normas; a compreensão de termos e conceitos-chave da ciência; e, ainda, a consciência dos impactos da ciência e da tecnologia na sociedade, e as escolhas políticas que serão inevitáveis. Para Miller (1983), esta a terceira dimensão de AC - a consciência dos impactos da ciência e da tecnologia na sociedade - era o que tornava a ideia de AC importante para a época. E da mesma forma, a consideramos hoje.

Autores como Santos e Mortimer (2009, p. 192), consideram que as "questões ambientais, políticas, econômicas, éticas, sociais e culturais relativas à ciência e à tecnologia são inerentes à atividade científica". Sua abordagem nos currículos de ciências pode ser feita de duas formas: pontual ou temática. Na abordagem pontual pode-se, exemplificar fatos e fenômenos do cotidiano relacionados aos conteúdos específicos, ilustrando aplicações tecnológicas, entre outros. Na abordagem temática, parte-se de um tema, um tópico, ou um assunto amplo como a poluição ambiental, o uso de recursos energéticos, etc, em que essas questões estejam imbricadas (SANTOS e MORTIMER, 2009). Essas questões são denominadas pelos referidos autores como aspectos sociocientíficos.

Para os mesmos autores, a abordagem de aspectos sociocientíficos ainda pode ser feita mediante a problematização, emergindo aspectos ambientais, políticos, éticos, sociais e culturais, de acordo com as ideias de Paulo Freire (SANTOS e MORTIMER, 2009).

Ressaltamos que neste trabalho discutimos apenas os aspectos da pesquisa que estão relacionados à terceira dimensão por nós proposta.

\section{Percurso metodológico}

Este estudo possui caráter qualitativo, baseado na interpretação de situações, textos e falas de todos os atores sociais envolvidos (ALVES-MAZZOTTI; GEWANDESZNAJDER, 2004; LÜDKE e ANDRÉ, 1986), e integra uma pesquisa maior, na qual investigamos se um curso de graduação de Química-Licenciatura, de uma universidade pública estadual do Paraná, desenvolve dimensões de Alfabetização Científica na formação de professores de Química. A abordagem qualitativa oferece condições para compreender, decodificar, explicar e enfatizar a multiplicidade do campo educativo e dos saberes escolares por meio de um contato direto com a situação em investigação (LÜDKE e ANDRÉ, 1986). Destacamos ainda, que a pesquisa qualitativa, como a presente, "[...] Não pretende testar hipóteses para comprová-las ao final da pesquisa; a intenção é a compreensão, reconstruir conhecimentos existentes sobre os temas investigados" (MORAES e GALIAZZI, 2013, p. 11).

Participaram da pesquisa 51 estudantes do curso de Química - Licenciatura, de uma universidade estadual do Paraná: $1^{a}$ série: 16 estudantes; $2^{2}$ série: 12 estudantes; $3^{a}$ série: 14 estudantes e $4^{\underline{a}}$ série: 09 estudantes, sendo que destes 51 , 35 são do gênero feminino e 16 do masculino.

Para a coleta de dados utilizamos dois instrumentos: entrevistas semiestruturadas a partir de um formulário com perguntas e questionário escrito. Quanto às entrevistas, 0 formulário continha 13 questionamentos e foram realizadas com os estudantes da 4. a série 
do curso, cada uma com duração média de 60 minutos, em local escolhido pelo participante, com seu registro sendo feito aparelho MP3. Quanto ao questionário escrito, constituído de 26 (vinte e seis) questões abertas e de múltipla escolha, que foram respondidos por estudantes de todas as séries do curso. Os questionários e as entrevistas foram transcritos literalmente e analisados de acordo com os pressupostos da Análise Textual Discursiva (MORAES e GALIAZZI, 2013).

Para os autores Gerhardt et al (2009), questionários são instrumentos de coleta de dados constituídos por uma série ordenada de questões, perguntas, respondidas de forma escrita, sem a necessidade da presença do pesquisador. Já as entrevistas constituem "uma técnica de interação social, uma forma de diálogo assimétrico, em que uma das partes busca obter dados, e a outras e apresenta como fonte de informação" (GERHARDT et al, 2009 , p. 72). Nas entrevistas do tipo semiestruturada, como a que utilizamos nesta pesquisa, os pesquisadores organizam "um conjunto de questões (roteiro) sobre o tema que está sendo estudado, mas permite, e às vezes até incentiva, que o entrevistado fale livremente sobre assuntos que vão surgindo como desdobramentos do tema principal" (GERHARDT et al, 2009, p. 72).

Entretanto, no presente trabalho apresentamos somente os resultados obtidos, principalmente do conteúdo de respostas referentes a duas questões, uma do questionário e uma da entrevista. Sendo que o questionário foi respondido por todos os 51 licenciandos, abrangendo todas as séries do curso. $\mathrm{E}$ as entrevistas atingiram apenas nove (9) acadêmicos da quarta série do curso. No caso da questão respondida no questionário, ela teve a seguinte redação: Considera ser possível que os avanços da ciência possam resolver algumas questões ambientais, como o acúmulo de resíduos sólidos (lixo), por exemplo? ( ) Sim. ( ) Não. Obs.: Em qualquer uma das alternativas, justifique sua resposta. No caso da questão da entrevista, que teve o objetivo de investigar a compreensão dos fatores envolvidos nas diversas questões ambientais, tais como as políticas e econômicas, a sua formulação foi a seguinte: Sobre as questões ambientais, tais como o destino do lixo nas grandes cidades, você considera que uma solução dada pela ciência química ou biológica, por exemplo, resolveria o problema? Por quê? É importante deixar claro, contudo, que não se trata de analisar unicamente uma questão, mas que esta foi a principal delas no que tange à dimensão de $A C$ aqui apresentada.

\section{Resultados}

O percurso da pesquisa como um todo nos permitiu o estabelecimento de seis (6) temas, com suas respectivas categorias. Neste trabalho, apresentamos, contudo, apenas um destes temas e suas categorias, o qual foi denominado assim: "aspectos sociocientíficos e as questões ambientais". No Quadro 1, sistematizamos o referido tema, as categorias correspondentes e as unidades de sentido. Na sequência, discutimos alguns fragmentos de fala dos estudantes, aqueles que são, para nós, destaques. 
Quadro 01 - Resumo do tema e respectivas categorias obtidas dos instrumentos respondidos pelos estudantes

\begin{tabular}{|l|c|}
\hline \multicolumn{2}{|l|}{ TEMA: Aspectos sociocientíficos e a questão ambiental } \\
\hline Categorias & $\begin{array}{l}\text { № de unidades } \\
\text { de sentido }\end{array}$ \\
\hline 1: Aspectos salvacionistas da ação da Ciência e da Tecnologia & 18 \\
2: Estudo e pesquisa em busca de soluções & 15 \\
3: Identificação de aspectos sociocientíficos & 10 \\
4: Educação e Conscientização & 21 \\
5: Consumismo e aumento do lixo & 04 \\
\hline
\end{tabular}

Fonte: Autoria própria

Em nossa investigação, os estudantes foram questionados quanto à possibilidade de os avanços da ciência apresentarem soluções para os problemas ambientais, como o dos resíduos sólidos, por exemplo. Em resposta, obtivemos ideias ingênuas que nos revelam "[...] uma quase crença na ciência como resolução de problemas da humanidade, isenta de outros interesses que não seja a melhoria da vida" (LEITE, 2015, p. 149). Os aspectos políticos e sociais são mencionados poucas vezes e outros, como os econômicos, não são citados.

Em LEITE (2015) discutimos com base nos mitos debatidos por Auler e Delizoicov (2001). Estes autores, em investigação de compreensões de professores de Ciências sobre as interações entre Ciência, Tecnologia e Sociedade, examinaram três mitos, descritos anteriormente: (i) superioridade do modelo de decisões tecnocráticas; (ii) perspectiva salvacionista da Ciência e Tecnologia; e (iii) determinismo tecnológico, sendo a chamada Neutralidade Científica o "mito original".

Na primeira categoria - 1 Aspectos salvacionistas da ação da Ciência e da Tecnologia -, é possível discutir a perspectiva salvacionista de Ciência e Tecnologia, e a crença de que ambas sempre conduzem ao progresso, ou seja, à solução dos problemas: "[...] são sempre criadas para solucionar os problemas da humanidade, de modo a tornar a vida mais fácil". Assim, eis um dos mitos apontados por Auler e Delizoicov (2001, p. 4), conforme algumas respostas destacadas a seguir:

A ciência sempre visa o desenvolvimento de forma concreta e coerente, além de resolver problemas e incógnitas. O lixo é um problema em todo mundo, por isso a ciência estuda formas de reaproveita-lo e minimizá-Io. E05-1 QUEST

[...] o avanço da ciência visa criar equipamentos de reciclagem mais baratos. E18-2 QUEST

Sim, pois a ciência é utilizada sempre pra resolver questões ambientais. E21-2 QUEST

Porque hoje já temos uma grande evolução e acredito que isso só tem a melhorar, e com os avanços as questões ambientais serão melhores. E39-3 QUEST 
Nos trechos mencionados é possível perceber que se trata de um entendimento equivocado do papel que a ciência e a tecnologia exercem em nossa sociedade, baseado na crença de que ambas sempre trarão benefícios para a humanidade. Ou seja, os estudantes acreditam que a ciência, como uma instituição, trará soluções para tais problemas, e sem a influência de outros fatores.

O mesmo se pode mencionar para a segunda categoria, que trata do Estudo e pesquisa em busca de soluções, a qual, além de ser relacionada ao caráter salvacionista da ciência e da tecnologia, também se relaciona ao mito, ou seja, ao determinismo tecnológico segundo o qual os avanços da ciência e da tecnologia sempre contribuem para o bem-estar da humanidade, para a melhoria da qualidade de vida, sendo esse determinismo considerado determinante o desenvolvimento da humanidade. Tal como o anterior, este entendimento também é tido como isento de influências sociais.

Pois vem sendo estudado técnicas em prol da melhoria do ambiente e acabar com o acúmulo de resíduos sólidos. Buscando assim formas de melhorias. E03-1 QUEST

[...] com o avanço do conhecimento com a evolução das tecnologias as questões ambientais e outros problemas da sociedade irão se resolver. E04-1 QUEST

Os estudos da ciência avançam constantemente e acredito que logo serão desenvolvidos novos equipamentos que aumentem a velocidade de degradação desses resíduos que estão sendo acumulados ao longo do tempo. E09-1 QUEST

A ciência e a tecnologia estão em constantes avanços, acredito que este problema ainda será resolvido. E30-3QUEST

Não sei se resolveria, mas ajudaria muito. Porque a ciência utiliza de meios para que esse impacto ambiental diminua, [...]. Então a parte de, digamos substâncias, metodologias, tecnologias, esse apoio todo que a ciência consegue dar, eu acho fundamental [...].E49-4 ENT

[...] Avanços tecnológicos terão um peso fundamental na resolução de algumas questões. E50-4 QUEST

É possível evidenciar que ambas as categorias se direcionam às ideias contidas nos mitos discutidos por Auler e Delizoicov (2001) e tendem a enfatizar traços de uma AC Reducionista no curso investigado, pois "[...] toda a atividade científica envolvida na possível 'resolução' do problema proposto foi pautada nas decisões de ciência e tecnologia e seu desenvolvimento, sendo até mesmo atribuída a esse possível desenvolvimento" (LEITE, 2015, p. 151).

Contudo, na categoria 3 Identificação de aspectos sociocientíficos, em contraposição às anteriores, os excertos nos mostram que alguns estudantes ponderam sobre as ações da ciência como integrantes de um sistema maior e com a presença de outros aspectos envolvidos no processo complexo, que engloba vários interesses. É difícil afirmar que os mitos não estejam presentes, e explicitamente não estão. Todavia, com base nos mesmos autores, é possível perceber que as relações CTS estão presentes, mesmo que de forma ainda tímida.

Eu até acho que os avanços científicos podem auxiliar em questões ambientais, muito embora acredite que na sociedade que vivemos as questões ambientais estão mais relacionadas com o cunho político. E35-3QUEST 
hum:.... ciência, sociedade... ah, tem a questão política também... porque tudo o que vai ser feito tem que ter algum tipo de, não de beneficiamento, mas tudo o que vai ser aprovado tem algum interesse da política, ela que vai falar esse tal vai ser aprovado, porque isso envolve também além da sociedade as políticas pra promover essa modificação, [...]. E43-4

Depende se o avanço da tecnologia for tanto benéfico para a sociedade, quanto para o meio ambiente, este irá resolver estas questões ambientais. Mas se o avanço for apenas para melhorias da sociedade como: desenvolvimento de carros, celulares, roupas, eletrodomésticos entre outros não irá resolver as questões ambientais. E45-4 ${ }_{\text {QUEST }}$

Ai, aí ia depender de muita coisa, porque eles poderiam dar a sugestão, mas se o, no caso, sistema, que são... ah a economia, o governo, aceitasse também, pra implementar, porque não adianta nada também. [...] Porque só a ciência trazer uma solução, só ela, não consegue... só a pesquisa dela... vai ter mais coisa no entorno. E50-4 $4_{\mathrm{ENT}}$

Os interesses políticos e econômicos são mencionados como fatores que, de alguma maneira, influenciam ações como as vinculadas às questões ambientais:

Não... não adianta a ciência dá solução e não ter investimento pra que isso se concretize. Então, não adianta nada eu chegar à prefeitura e falar olha, tá errado, a solução é isso e faça isso e guardar na gaveta... então não é uma questão que vai depender do cientista ou da ciência, mas precisa de ajuda maior pra que aconteça. Financeira também. [...] a parte política... parte política é... na verdade é parte política e lei, porque hoje em dia pra você conseguir fazer... tá fazendo as coisas em questão do meio ambiente, poluição, porque tá doendo no bolso... infelizmente... a pessoa só vai cuidar pra cuidar do bolso... então acho que cobrança também [...]. E44-4

[...]que ainda não é só dele... eu acho que precisa um... não sei..[...]. eu acho que precisa envolver muito:: o governo... acho que precisa envolver a sociedade, precisa envolver vários órgãos é::... sei lá... necessita-se algo muito, mas muito abrangente mesmo, envolver principalmente políticas públicas, que as políticas públicas poderiam envolver noventa por cento ou até todos os problemas de uma sociedade, só que elas não são exercidas por ignorância do povo que elege e por ignorância do povo que tá eleito. E46-4 $4_{\mathrm{ENT}}$

[...] eu acho que infelizmente, eu acho que o financeiro. Porque assim, olha, hoje em dia gasta-se MUITO, nessa parte sabe, de poluição, em geral, então a parte financeira pesa bastante, no caso de governantes, Mas também, problema de saúde pública, das pessoas adoecerem mais, necessitarem mais de auxílio, de atendimento, de tratamento de efluentes, enfim, eu acho que o impacto todo, gasta-se muito, então investindo na ciência pra conseguir minimizar o problema e não gastar tanto, cada vez isso, virando um bolo e aumentando mais, é:: seria interessante. Eu acho que eles pensam mais ou menos por aí, deveriam. E49$4_{\text {ENT }}$

Consideramos de grande importância que os estudantes percebam que apenas aspectos técnicos, científicos não são suficientes para a proposição de soluções. Como várias outras, a questão ambiental está associada a fatores econômicos, políticos e culturais, entre outros (BRÜGGER, 2004). Entretanto, os estudantes denotam ainda uma fragmentação nas ideias relacionadas ao assunto, pois ainda há certa dificuldade em explicitar como essas relações se estabelecem.

Também avultamos a crença de que a conscientização da população em geral seria o fator determinante para a resolução de processos dessa natureza, o que leva à quarta categoria. 
Também avultamos a crença de que a conscientização da população em geral seria o fator determinante para a resolução de processos dessa natureza, categoria 4 Educação e Conscientização, ou seja, mesmo sendo complexo, o processo teria uma solução relativamente simples se houvesse conscientização e colaboração das pessoas envolvidas. É o que evidenciam os relatos a seguir:

Porque o acúmulo de lixo é uma questão de conscientização, as pessoas tem que consumir e aprender que muita coisa pode ser reciclável. O avanço da ciência visa criar equipamentos de reciclagem mais barato. E18-2QUEST

Pensando em maneiras melhores que não seja o descarte incorreto. E os profissionais da educação estimulando seus alunos a pensar diferente sobre a questão ambiental. E252QUEST

Com a situação que o mundo se encontra e como isso irá ficar pior, não consigo visualizar que os avanços da ciência possam dar conta de tudo, sem a conscientização das pessoas [...] E32-3QUEST

[...] então acho que não é uma questão só de responsabilidade do governo e de duas ou três pessoas que estão querendo fazer isso mas da população em geral... ser consciente [...].E44-4ENT

[...] Porque as pessoas não têm consciência ainda. Eu vou citar um exemplo do que acontece em casa. Eu moro com mais duas pessoas, as mesmas cursam química e a gente tem lá em baixo o lixo, onde você joga o lixo normal e onde você joga o lixo reciclável, só eu que jogo o lixo reciclável. Então é uma questão cultural que as pessoas ainda, parece que não tomaram consciência da dimensão disso [...]. E45-4 $4_{\mathrm{ENT}}$

Sem a conscientização não. P: conscientização de quem? E48: de todo mundo. Porque eu acho que tem muita gente que, ai, qualquer coisinha já é descartável... seja celular, computador, se... cada vez mais a gente vê que tem mais lixo, mais lixo. A quantidade de lixo que é produzida por pessoa tá aumentando a cada ano. E48-4 ENT

Percebemos que, embora mencionem alguns exemplos concretos, os estudantes ainda estão bastante atrelados à ideia romântica de conscientização, como se o fato de estar consciente sobre o que é ou não correto fazer já caracterizasse alguma modificação. Muitos aspectos da Educação Ambiental, em uma representação também romântica, são pautados dessa maneira, simplificando as ações maiores e realmente efetivas, as quais são reduzidas a ações e comportamento de conscientização. A respeito disso, autores como Sato (2001) afirmam que, diferentemente, ninguém conscientiza ninguém, nem é esse o objetivo da Educação Ambiental. Tal ideia provém de uma maioria reprodutora de discursos sem fundamentação crítica. Para essa autora, o mundo social não pode funcionar apenas em termos de consciência, mas também de práticas.

Segundo a referida autora, nossas predisposições são consideradas academicistas e provêm da arrogância intelectual munida de capital cultural e do discurso, que se configura como instrumento de poder. Entretanto, as comunidades e os grupos, por exemplo, possuem conhecimentos próprios, e não utilizam uma linguagem acadêmica para que esse saber seja legitimado. Logo, ninguém pode proporcionar a consciência a alguém. As pessoas são seres historicamente construídos, que capturam a realidade na medida em que forem capazes de se conceberem em seu próprio mundo (SATO, 2001). 
Na categoria 5 Consumismo e aumento do lixo, estão agrupados os excertos que atribuem ao consumismo a razão dos problemas causados pelo lixo. Consideramos relevante o destaque a essas respostas, pois revelam que os estudantes ao menos conseguem perceber que outros fatores, maiores e mais complexos, estão envolvidos em situações, como a do lixo, já que o ato de consumir caracteriza a sociedade capitalista, moderna e tecnológica em que vivemos:

A ciência tem avançado e com ela o acúmulo de lixo vem crescendo, pois as pessoas querem e procuram estar sempre se atualizando e com isso as coisas vão ficando cada vez mais descartáveis. E17-2QUEST

Sim, pois através da química podemos desenvolver novos materiais biodegradáveis ou outros trabalhos que possam colaborar com o meio ambiente. E19-2QUEST

[...] Porque as pessoas vão se desfazendo daquilo, muitas vezes não compensa arrumar, porque o valor fica superior, ou equivalente. E daí, pra onde vai tudo isso? Então hoje em dia se gera mais lixo também pela facilidade de acesso pra você comprar essas tecnologias, e por precisar mesmo, porque não tem mais qualidade. [...] E49-4 $4_{\mathrm{ENT}}$

De acordo com alguns excertos, a sociedade vive a época dos descartáveis e isso é fato. Tanto a ciência quanto a tecnologia, apesar de trazerem grandes contribuições, criam também necessidades nos indivíduos:

[...] tornando-nos cegos pelos confortos que nos proporcionam cotidianamente seus aparatos e dispositivos técnicos. Isto pode resultar perigoso porque, nesta anestesia que o deslumbramento da modernidade tecnológica nos oferece, podemos nos esquecer que a ciência e a tecnologia incorporam questões sociais, éticas e políticas (BAZZO, 1998, p.142).

Diante do exposto, ressaltamos que o profissional da educação deve ter o compromisso de promover discussões acerca dessas questões, de forma a capacitar os estudantes da educação básica para a tomada de decisões conscientes (LEITE, 2015).

Agora, contudo, ao investigarmos como o curso de graduação promove tais discussões, encontramos as indicações das seguintes disciplinas, conforme o Quadro2. 
Quadro 02 - Disciplinas que discutem aspectos sociocientíficos citadas pelos estudantes

\begin{tabular}{|c|c|c|c|c|}
\hline \multicolumn{5}{|c|}{ Áreas } \\
\hline \multirow{7}{*}{ 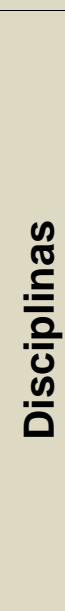 } & Área de Ensino & $\mathbf{N}^{*}$ & Áreas Específicas & $\mathbf{N}^{*}$ \\
\hline & Didática & 4 & Fundamentos de Química & 9 \\
\hline & Educação Química Ambiental & 7 & Metodologia Científica & 2 \\
\hline & Metodologia e Instrumentação & 14 & Química Analítica & 4 \\
\hline & & & Química Inorgânica & 1 \\
\hline & $\begin{array}{l}\text { Prática de Ensino e Estágio } \\
\text { Supervisionado A e/ou B }\end{array}$ & 1 & Química Orgânica & 1 \\
\hline & Projetos de Ensino I e/ou II & 1 & & \\
\hline
\end{tabular}

${ }^{*}$ Número de indicações pelos estudantes

Fonte: Adaptado de LEITE (2015)

Ao discutirmos as formas de trabalho das áreas, percebemos que, na área específica, os temas sociocientíficos são contemplados de maneira associada aos aspectos técnicos, como o descarte correto de resíduos gerados no laboratório, como os seguintes excertos:

Fundamentos da Química, quando falado de usinas nucleares, acidentes radioativos, descarte de pilhas em eletroquímica. E orgânica ao falar de polímeros também foi relacionado o descarte. E37-3QUEST

[...] onde muito se fala em reduzir ao máximo (quando possível, não gerar) os resíduos em práticas experimentais, pois estes podem agredir de forma violenta o ambiente e prejudicar a saúde das pessoas! E46-4 EST

Entretanto, as respostas dos estudantes indicam que as disciplinas da área de ensino não apenas discutem essas questões, e, sim, promovem a reflexão nas aulas, tanto das atividades da química na sociedade quanto do ensino de química abrangendo essas questões, enquanto as disciplinas da área específica apontam e destacam questões pontuais com pouca discussão e reflexão sobre a temática:

[...] mas eu volto a repetir que foi nas disciplinas da educação. Principalmente na divulgação da ciência ${ }^{3}$ ((risos))... é que gerava muito discussão, porque tudo que era publicado, era divulgado, era nessas linhas entendeu, então sempre as discussões eram muito ali... daí as questões ambientais na disciplina de educação ambiental. Então... sempre nessas disciplinas. Sempre, sempre, sempre. E50-4 $4_{\mathrm{ENT}}$

Assim, é possível dizer que "[...] neste curso, a área de ensino é a que mais se preocupa com os temas sociocientíficos, no sentido de articular todos os aspectos envolvidos em cada situação, sejam eles éticos, políticos, sociais, econômicos e científicos" (LEITE e RODRIGUES, 2014, p. 1).

\footnotetext{
${ }^{3}$ A disciplina de Divulgação Científica foi ofertada três vezes (2011, 2012 e 2013) como disciplina optativa.
} 
Para uma análise geral da distribuição das unidades de sentido, apresentamos o Gráfico 1:

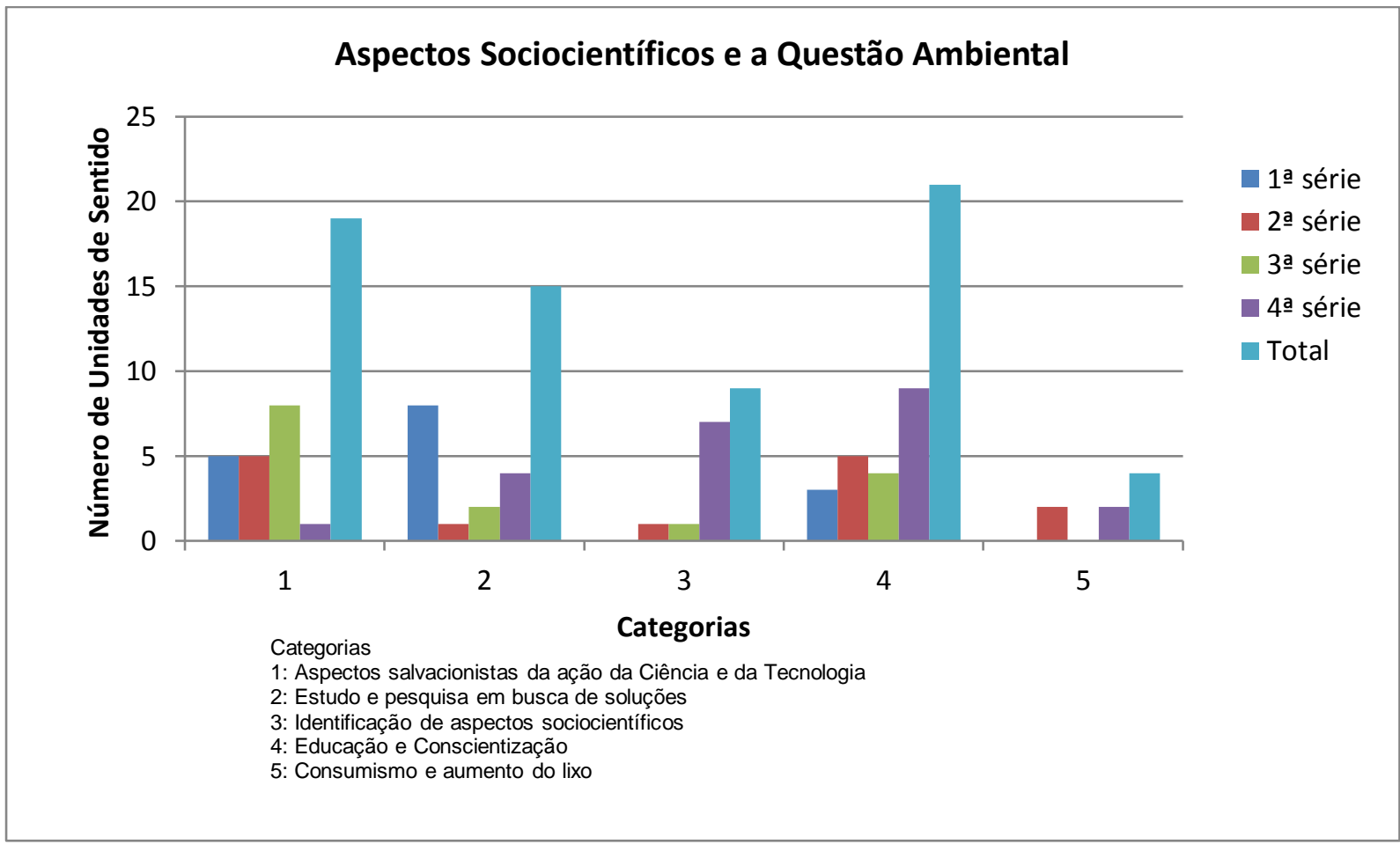

Gráfico 1: composição do tema - número de unidades de sentido para cada uma das categorias distribuídas nas séries do curso

Fonte: Autoria própria

Podemos observar que as categorias mais recorrentes foram a 4, 1 e 2, nessa ordem de importância. Diante desses resultados, é possível notar que, segundo os estudantes, aposta-se fortemente na educação para a solução dos problemas, especialmente em estratégias pautadas na conscientização das pessoas, categoria 4,. Isso revela um entendimento romântico, conservador, de toda a complexidade ambiental, bastante enfatizado, inclusive por estudantes de final de curso. Tal constatação é corroborada pelos demais resultados, categorias 1 e 2 , nas quais se considera a ciência e a tecnologia como conquistas/recursos que trarão benefícios necessários, sem questionamentos ou dúvidas, e isso baseado em estudos para a solução dos problemas. Felizmente, contudo, é possível observar que o aspecto salvacionista da ciência e da tecnologia não foi tão salientado por estudantes da $4^{a}$ série do curso.

As ideias presentes nos excertos, e sistematizadas no gráfico, nos revelam uma ausência do caráter sociocientífico nos processos relacionados à ciência, uma vez que grande parte das unidades de sentido, ou seja, das respostas dos estudantes, que compõem essas categorias, contrapõem as ideias descritas pela categoria 3, que ressaltam a identificação desses aspectos, mas que é composta por poucas unidades de sentido, quando comparada às demais.

\section{Considerações Finais}

O entendimento dos aspectos sociocientíficos pelo professor de Química é de extrema relevância, tendo em vista que ele deve mobilizar em sala de aula diversos conhecimentos sobre assuntos políticos, sociais, culturais, além do científico e pedagógico. 
São esses conhecimentos que irão favorecer o crescimento pessoal e social dos estudantes, tornando-os capazes de atuar em sociedade de forma consciente.

No que se refere à identificação de aspectos sociocientíficos nas situações cotidianas, os licenciandos participantes deste estudo apresentaram indícios de dificuldade nesse processo, uma vez que grande parte de suas opiniões revela entendimentos conservadores, com grande atribuição de aspectos salvacionistas à Ciência e à Tecnologia. Também foi possível destacar as ideias com relação ao papel da educação no processo de conscientização das pessoas, o que, para esses estudantes, ainda é a melhor solução para os problemas ambientais. Além disso, os licenciandos manifestaram algumas ideias românticas de educação ambiental e meio ambiente, complementando o valor atribuído ao processo de conscientização.

Diante disso, somos levados a supor que os estudantes ignoram as relações importantes entre os aspectos sociocientíficos e ambientais. Entretanto, ou as ignoram no sentido de não saber que realmente existem e influenciam nos processos como um todo, ou optam por não destacá-las em suas respostas. De acordo com as respostas, acreditamos que a primeira alternativa seja a mais provável.

Sendo assim, fica validado o nosso pressuposto de que essa dimensão de AC clareza dos aspectos sociocientíficos envolvidas nas diversas situações da vida - deva ser desenvolvida nos cursos de Licenciatura das áreas de Ciências Naturais, e isso também corrobora nossa posição de defender o desenvolvimento da AC nesses cursos. Mesmo assim, é necessário refletir sobre as estruturas desses cursos, posto que, conforme apresentamos neste trabalho, os aspectos sociocientíficos são abordados quase tão somente pelas disciplinas que compõem a área de ensino, o que caracteriza uma formação relativamente incompleta, tendo em vista que todas as disciplinas do curso devem ser corresponsáveis pela formação integral do licenciando, futuro professor de Química.

\section{REFERÊNCIAS}

ALVES-MAZZOTTI, A. J.; GEWANDSZNAJDER, F. O Método nas Ciências Naturais e Sociais: Pesquisa Qualitativa e Quantitativa. 2. ed. São Paulo: Thomson, 2004.

AULER. D.e DELIZOICOV. D. Alfabetização científico-tecnológica para quê? Ensaio Pesquisa em Educação em Ciências, v. 3, n. 2, p. 1-13, 2001.

AZEVEDO, R. O. M. et al. Formação inicial de professores da educação básica no Brasil: trajetória e perspectivas. Diálogo Educacional, v. 12, n. 37, p. 997-1026, 2012.

BAZZO, W. A. Ciência, tecnologia e sociedade: e o contexto da educação tecnológica. Florianópolis: Ed. da UFSC, 1998.

BRÜGGER, P. Educação ou adestramento ambiental. 3. ed. Chapecó: Argos; Florianópolis: Letras Contemporâneas, 2004.

FOUREZ, G. Alfabetización científica y tecnológica: acerca de las finalidades de La enseñanza de las ciências. Buenos Aires: Ediciones Colihue, 1997.

GERHARDT, T. E. et al. Estrutura do projeto de pesquisa. In: GERHARDT, T. E. e SILVEIRA, -D. T. (Orgs). Métodos de pesquisa. Porto Alegre: Editora da UFRGS, 2009. p. $68-88$. 
LEITE, R. F. Concepções de professores de química do ensino médio sobre educação ambiental. 2009. Dissertação de Mestrado - Universidade Estadual de Maringá, Centro de Ciências Exatas, Maringá, 2009.

\section{LEITE, R. F. Dimensões da alfabetização científica na formação inicial de} professores de química. 2015. Tese de Doutorado - Universidade Estadual de Maringá, Centro de Ciências Exatas, Maringá, 2015.

LEITE, R. F. e RODRIGUES, M. A. Abordagem de temas sociocientíficos na formação inicial de professores de química. In: Anais do II Congresso Internacional de Educação em Ciências, 15 anos do Journal of Science Education, 2014. v. 15. p. 208-208.

LÜDKE, M.; ANDRÉ, M. E. D. A. Pesquisa em educação: Abordagens qualitativas. São Paulo: EPU, 1986.

MILLER, J. D. Scientific literacy: a conceptual and empirical review. Daedalus: Journal of the American Academy of Arts and Sciences, v. 112, n. 12, p. 29-48, 1983.

MORAES, R. e GALIAZZI, M.C.. Análise textual discursiva. ljuí, RS: Ed. Unijuí, 2013.

ROSSI, A.V. e FERREIRA, L. H. A expansão de espaços para formação de professores de química: atividades de ensino, pesquisa e extensão a partir da Licenciatura em Química. In: ROSA, M. I. P. e ROSSI, A. V. (Org.). Educação química no Brasil: memórias, política e tendências. Campinas, SP: Átomo, 2008. p. 127-142.

SANTOS, W. L. P. Educação científica na perspectiva de letramento como prática social: funções, princípios e desafios. Revista Brasileira de Educação, Rio de Janeiro, v. 12, n. 36, p. 474-492, 2007.

SANTOS, W. L. P; MORTIMER, E. F. Abordagem de aspectos sociocientíficos em aulas de ciências: possibilidades e limitações. Investigações em Ensino de Ciências, v. 2, 191-218, 2009.

SASSERON, L.e CARVALHO, A.M.P. de. Alfabetização científica: uma revisão bibliográfica. Investigações em Ensino de Ciências, Porto Alegre, v. 16, n. 1, p. 59-77, 2011.

SATO, Michèle. Debatendo os desafios da educação ambiental. In: I Congresso de Educação Ambiental Pró Mar de Dentro. Rio Grande: Mestrado em Educação Ambiental, Furg\& Pró Mar de Dentro, 17-21/maio/2001. Disponível em: <http://www.partes.com.br/20 01/11/24/debatendo-os-desafios-da-educacao-ambiental-2/>. Acesso em 15 fev. 2017. 